\title{
Airway reversibility in asthma and phenotypes of Th2-biomarkers, lung function and disease control
}

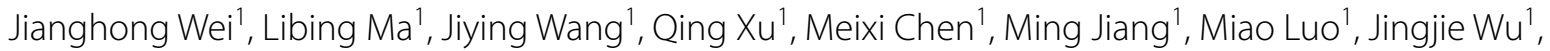
Weiwei She ${ }^{1}$, Shuyuan Chu $u^{1,2^{*}}$ and Biwen Mo ${ }^{1,2^{*}}$

\begin{abstract}
Background: High bronchodilator reversibility in adult asthma is associated with distinct clinical characteristics. In this study, we aim to make a comparison with T-helper 2 (Th2)-related biomarkers, lung function and asthma control between asthmatic patients with high airway reversibility (HR) and low airway reversibility (LR).

Methods: Patients with asthma diagnosed by pulmonologist according to Global Initiative for Asthma guidelines were recruited from the outpatient department of our hospital from August 2014 to July 2017. Patients were divided into $H R$ and $L R$ subgroups based on their response to bronchodilators of lung function ( $H R=\triangle$ forced expiratory volume in one second (FEV1) postbronchodilator $\geq 20 \%$ ). Blood eosinophil count and serum lgE level, which are biomarkers of T-helper (Th)-2 phenotypes, were detected for patients. Asthma Control Test (ACT) was used to assess asthma control after the first-month initial treatment.

Results: A total of 265 patients with asthma were followed 1 month after initial treatment. HR group shows a higher level of Th2-high biomarkers (blood eosinophil count (10^9/L): $0.49 \pm 0.28$ vs $0.36 \pm 0.19, P<0.01$; lgE (ng/ ml): $1306 \pm 842$ vs $413 \pm 261, P<0.01$ ), lower baseline lung function (FEV1\%pred: $51.91 \pm 19.34 \%$ vs $60.42 \pm 19.22 \%$, $\mathrm{P}<0.01$; forced expiratory flow (FEF) $25-75: 0.76 \pm 0.37$ vs $1.00 \pm 0.67, \mathrm{P}<0.01$; FEF25-75\%pred: $21.15 \pm 10.09 \%$ vs $29.06 \pm 16.50 \%, P<0.01$ ), and better asthma control (ACT score: $22 \pm 4$ vs $20 \pm 4, P=0.01$ ) than LR group. HR was associated with a decreased risk of uncontrolled asthma after the first-month initial treatment (adjusted OR: 0.12 [95\% confidence intervals: 0.03-0.50]).

Conclusions: HR is a physiologic indicator of lower lung function and severe small airway obstruction, and is more related with an increased level of Th2-biomarkers than LR. Moreover, HR may indicate controlled asthma after the firstmonth initial treatment. This finding may contribute to identification of asthma endotype.
\end{abstract}

Keywords: Asthma, Airway reversibility, Th2-biomarkers, Lung function, Asthma control

\section{Background}

Airway bronchodilator reversibility is the characteristic that differentiates asthma population from patients with irreversible obstructive lung diseases [1]. It has been emerged as a characteristic to categorize asthma patients into different phenotype [2], and a physiologic

\footnotetext{
*Correspondence: emilyyuanchu@163.com; 1042587352@qq.com ${ }^{1}$ Department of Respiratory and Critical Care Medicine, Affiliated Hospital of Guilin Medical University, Guilin 541001, Guangxi, China Full list of author information is available at the end of the article
}

biomarker associated with co-morbidities of asthma patients [3]. Interestingly, the high airway bronchodilator reversibility was found as a physiologic indicator for reduced lung function, and was associated with elevated Th2-biomarkers [4]. Thus, airway bronchodilator reversibility may be a crosslinking point in understanding the diversity of asthma endotype, and then identify profiles to guide treatment [5]. However, that previous study didn't investigate obstruction in small airway, or asthma control after the initial treatment according to the Global Initiative for Asthma guidelines (GINA) 
alone [1]. Therefore, we conducted this hospital-based cohort study to investigate immune pathway biomarkers, obstruction in small airway, and disease control after the initial treatment in asthma patients with high or low airway reversibility.

\section{Methods}

From August 2014 to July 2017, adult patients with asthma diagnosed by pulmonologists at the first time according to the definition of GINA [1] were recruited in the study from the Affiliated Hospital of Guilin Medical University, Guilin, China. Blood eosinophil count and serum IgE level were tested. Asthma control was assessed in terms of Asthma Control Test (ACT) after the firstmonth initial treatment with a face-to-face interview by pulmonologists [6,7]. The study protocol was approved by the Institutional Review Board at the Affiliated Hospital of Guilin Medical University, and conformed to the declaration of Helsinki. Written informed consent was obtained from each subject.

Inclusion criteria in the present study were as following: (1) age between 18 and 65 years, (2) forced expiratory volume in one second (FEV1) \% predicted less than $80 \%$, (3) reversibility in FEV1 12\% (and at least $200 \mathrm{ml}$ ) following administration of a short-acting $\beta$-agonist, (4) no evidence of active infection, (5) no medical conditions associated with immune suppression. Patients were excluded if they had chronic obstructive pulmonary disease (COPD) or asthma-COPD overlap [8], had a history of intubation within 3 years of enrollment, or had obstructive sleep apnea.

Subjects were classified into high airway reversibility (HR) group and low airway reversibility (LR) group. The HR group included patients with $a \geq 20 \%$ increase in FEV1 following administration of a short-acting bronchodilator during screening and baseline pulmonary function testing. The LR group included those with reversibility below that level [2].

Group data were expressed as the mean \pm standard deviation (SD). Significant differences were evaluated using independent-samples $t$ test or Chi square test. The associations between asthma control and clinical characteristics were explored with unconditional logistic regression models with LOGISTIC procedure in SAS 9.4 (SAS Institute Inc., Cary, North Carolina, USA). The results were presented as odds ratios (OR) and 95\% confidence intervals $(\mathrm{CI})$. $\mathrm{P}$ values $<0.05$ were considered to be statistically significant.

\section{Results}

Figure 1 shows the subject selection process. We excluded subjects if they had no record of lung function responding to bronchodilators, blood eosinophil count, serum IgE level, or ACT score. A total of 265 subjects were selected for final analyses.

Demographics characteristics for all patients were summarized in Table 1. HR and LR groups were similar in percentages of male, smoker and subjects having history of allergy, age and body-mass index (BMI). All patients were received inhaled corticosteroid (ICS) combined long-acting inhaled $\beta 2$-agonist (LABA) as initial treatment.

Moreover, Table 1 illustrates the difference of Th-2 phenotypes, lung function and asthma control between HR and LR groups. In HR group, eosinophil count in blood and IgE level in serum were higher than those in LR group (eosinophil count $\left(10^{\wedge} 9 / \mathrm{L}\right)$ : $0.49 \pm 0.28$ vs $0.36 \pm 0.19 ; \mathrm{IgE}(\mathrm{ng} / \mathrm{ml}): 1306.0 \pm 841.5$ vs $413.4 \pm 261.6$. All $\mathrm{P}$ values $<0.01)$. Moreover, the base lung function in HR group was worse than that in LR group (FEV1\%pred: $51.91 \pm 19.34 \%$ vs $60.42 \pm 19.22 \%$; forced expiratory flow (FEF)25-75: $0.76 \pm 0.37$ vs $1.00 \pm 0.67 ; \quad$ FEF $25-75 \%$ pred: $\quad 21.15 \pm 10.09 \%$ vs $29.06 \pm 16.50 \%$. All $\mathrm{P}$ values $<0.01$ ). In addition, $\mathrm{HR}$ group was showed better asthma control than LR group after the first-month initial treatment (ACT score: $22 \pm 4$ vs $20 \pm 4, \mathrm{P}=0.01$ ).

We further explored the association between $\mathrm{HR}$ and asthma control after the first-month initial treatment. Table 2 shows that HR was associated with a decreased

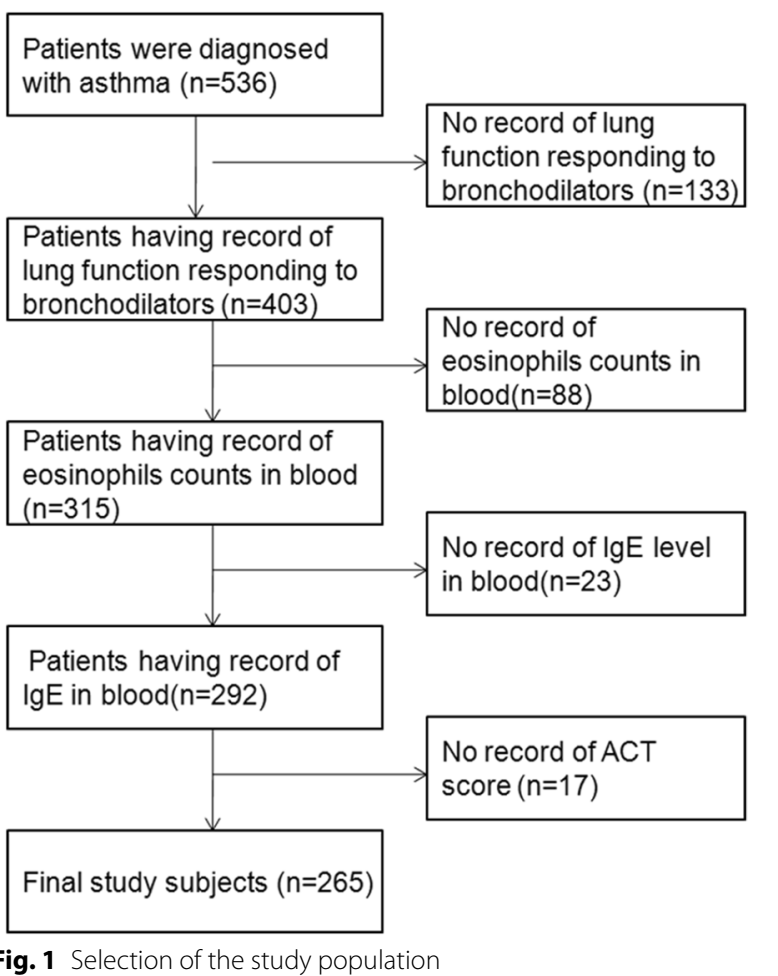


Table 1 Comparison of patients between HR and LR groups

\begin{tabular}{|c|c|c|c|}
\hline Variable & HR group $(n=60)$ & LR group $(n=205)$ & $P$ value \\
\hline Gender (male) & $30(50.0 \%)$ & $82(40.0 \%)$ & 0.17 \\
\hline Age (years) & $45 \pm 10$ & $47 \pm 13$ & 0.23 \\
\hline BMI (kg/m2) & $22.80 \pm 3.34$ & $23.50 \pm 4.07$ & 0.23 \\
\hline Smoker (yes) & $21(35.0 \%)$ & $90(43.9 \%)$ & 0.22 \\
\hline Self-reported history of allergy (yes) & $7(11.7 \%)$ & $42(20.5 \%)$ & 0.12 \\
\hline Eosinophil count in blood $(10 \wedge 9 / \mathrm{L})$ & $0.49 \pm 0.28$ & $0.36 \pm 0.19$ & $<0.01$ \\
\hline lgE in blood (ng/ml) & $1306.0 \pm 841.5$ & $413.4 \pm 261.6$ & $<0.01$ \\
\hline High-dose ICS+LABA & $2(3.3 \%)$ & $3(1.5 \%)$ & 0.69 \\
\hline \multicolumn{4}{|l|}{ Lung function test } \\
\hline \multicolumn{4}{|c|}{ Pre inhaling short-acting bronchodilator } \\
\hline $\mathrm{FVC}(\mathrm{L})$ & $3.01 \pm 2.62$ & $2.69 \pm 0.84$ & 0.14 \\
\hline FEV1 (L) & $1.52 \pm 0.62$ & $1.69 \pm 0.65$ & 0.08 \\
\hline FEV1\%pred (\%) & $51.91 \pm 19.34$ & $60.42 \pm 19.22$ & $<0.01$ \\
\hline FEV1/FVC (\%) & $55.43 \pm 11.97$ & $61.94 \pm 12.59$ & $<0.01$ \\
\hline $\operatorname{PEF}(\mathrm{L} / \mathrm{s})$ & $3.60 \pm 1.49$ & $3.88 \pm 1.61$ & 0.23 \\
\hline PEF\%pred & $43.70 \pm 16.80$ & $50.59 \pm 18.86$ & 0.01 \\
\hline FEF50 (L/s) & $0.97 \pm 0.50$ & $1.23 \pm 0.75$ & $<0.01$ \\
\hline FEF50\%pred (\%) & $23.05 \pm 12.18$ & $30.75 \pm 17.26$ & $<0.01$ \\
\hline FEF75 (L/s) & $0.39 \pm 0.40$ & $0.69 \pm 1.07$ & $<0.01$ \\
\hline FEF75\%pred (\%) & $19.05 \pm 9.16$ & $25.96 \pm 16.08$ & $<0.01$ \\
\hline FEF25-75 & $0.76 \pm 0.37$ & $1.00 \pm 0.67$ & $<0.01$ \\
\hline FEF25-75\%pred (\%) & $21.15 \pm 10.09$ & $29.06 \pm 16.50$ & $<0.01$ \\
\hline \multicolumn{4}{|c|}{ Post inhaling short-acting bronchodilator } \\
\hline FVC (L) & $2.73 \pm 0.99$ & $2.79 \pm 0.85$ & 0.67 \\
\hline FEV1 (L) & $2.11 \pm 0.98$ & $1.84 \pm 0.68$ & 0.02 \\
\hline FEV1\%pred (\%) & $72.45 \pm 32.46$ & $67.56 \pm 26.88$ & 0.23 \\
\hline FEV1/FVC (\%) & $81.69 \pm 38.48$ & $65.73 \pm 16.38$ & $<0.01$ \\
\hline PEF (L/s) & $4.12 \pm 1.54$ & $4.12 \pm 1.69$ & 0.98 \\
\hline PEF\%pred & $50.09 \pm 17.85$ & $53.12 \pm 18.96$ & 0.27 \\
\hline FEF50 (L/s) & $1.38 \pm 0.75$ & $1.46 \pm 0.81$ & 0.51 \\
\hline FEF50\%pred (\%) & $33.12 \pm 16.20$ & $36.69 \pm 18.64$ & 0.15 \\
\hline FEF75 (L/s) & $0.58 \pm 0.59$ & $0.76 \pm 0.97$ & 0.08 \\
\hline FEF75\%pred (\%) & $27.84 \pm 14.14$ & $31.28 \pm 18.86$ & 0.13 \\
\hline FEF25-75 & $1.15 \pm 0.65$ & $1.50 \pm 4.40$ & 0.28 \\
\hline FEF25-75\%pred (\%) & $30.99 \pm 16.96$ & $44.60 \pm 136.36$ & 0.17 \\
\hline FEV1 change ${ }^{a}$ & $30.13 \pm 9.69$ & $8.83 \pm 9.11$ & $<0.01$ \\
\hline ACT score & $22 \pm 4$ & $20 \pm 4$ & 0.01 \\
\hline
\end{tabular}

$H R$ high airway reversibility, $L R$ low airway reversibility, BMI body mass index, ICS inhaled corticosteroid, LABA long-acting b-agonist, FEV1 forced expiratory volume in $1 \mathrm{~s}$, FVC forced vital capacity, PEF peak expiratory flow, FEF forced expiratory flow, \%pred \% predicted, ACT asthma control test

a FEV1 change between pre- and post-inhaling short-acting bronchodilator

risk of uncontrolled asthma after the first-month initial treatment (adjusted OR for ACT score<20: $0.12[95 \%$ CI 0.03-0.50]). We furthermore assessed the association between asthma control and obstruction in small airway after inhaling short-acting bronchodilator. We found that FEF25-75 was associated with a decreased risk of uncontrolled or partly controlled asthma (adjusted OR for ACT score < 20: 0.07 [95\% CI 0.01-0.73]; adjusted OR for ACT score 20-24: 0.03 [95\% CI 0.01-0.71]).

\section{Discussions}

In our study, HR was more frequently associated with a higher level of Th2-biomarkers, lower lung function in baseline, and better asthma control after the first-month initial treatment than LR. Furthermore, HR and high 
Table 2 Adjusted and unadjusted relative risks of asthma control after the first-month initial treatment

\begin{tabular}{|c|c|c|c|c|c|c|}
\hline Exposure categories & Unadjusted OR & $95 \% \mathrm{Cl}$ & P values & Adjusted OR & $95 \% \mathrm{Cl}$ & P values \\
\hline \multicolumn{7}{|l|}{ Asthma uncontrolled $(n=105)$} \\
\hline$H R^{a}$ & 0.36 & $0.16-0.82$ & 0.02 & 0.12 & $0.03-0.50$ & $<0.01$ \\
\hline Eosinophil count in blood $\left(10^{\wedge} 9 / \mathrm{L}\right)^{a}$ & 1.10 & $0.18-6.58$ & 0.92 & 2.36 & $0.23-23.96$ & 0.47 \\
\hline $\operatorname{lgE}$ in blood $(\mathrm{ng} / \mathrm{ml})^{\mathrm{a}}$ & 1.00 & $0.99-1.00$ & 0.29 & 1.00 & $0.99-1.00$ & 0.89 \\
\hline FEF75 $(L / S)^{b, c}$ & 1.31 & $0.77-2.24$ & 0.32 & 0.82 & $0.41-1.63$ & 0.57 \\
\hline FEF75\%pred $(\%)^{b, c}$ & 1.01 & $0.99-1.04$ & 0.24 & 1.01 & $0.96-1.06$ & 0.81 \\
\hline FEF25-75 & 1.57 & $0.91-2.73$ & 0.11 & 0.07 & $0.01-0.73$ & 0.03 \\
\hline FEF25-75\%pred $(\%)^{b, c}$ & 1.02 & $1.02-1.05$ & 0.04 & 1.09 & $1.01-1.18$ & 0.02 \\
\hline \multicolumn{7}{|l|}{ Asthma partly controlled $(n=120)$} \\
\hline$H R^{a}$ & 0.59 & $0.27-1.28$ & 0.18 & 0.35 & $0.10-1.22$ & 0.10 \\
\hline Eosinophil count $\left(10^{\wedge} 9 / \mathrm{L}\right)^{\mathrm{a}}$ & 1.79 & $0.32-9.97$ & 0.51 & 2.85 & $0.31-26.12$ & 0.36 \\
\hline $\lg E(n g / m \mid)^{a}$ & 1.00 & $0.99-1.00$ & 0.93 & 1.00 & $0.99-1.001$ & 0.93 \\
\hline FEF75 $(L / S)^{b, c}$ & 1.30 & $0.76-2.20$ & 0.34 & 0.84 & $0.42-1.65$ & 0.60 \\
\hline FEF75\%pred $(\%)^{b, c}$ & 1.02 & $0.99-1.04$ & 0.18 & 1.01 & $0.95-1.06$ & 0.82 \\
\hline FEF $25-75^{b, c}$ & 1.52 & $0.87-2.62$ & 0.14 & 0.03 & $0.01-0.71$ & 0.03 \\
\hline FEF25-75\%pred $(\%)^{b, c}$ & 1.02 & $1.00-1.04$ & 0.06 & 1.07 & $1.00-1.15$ & 0.06 \\
\hline
\end{tabular}

$H R$ high airway reversibility, ACT asthma control test, FEF forced expiratory flow, \%pred \% predicted, FEV1 forced expiratory volume in $1 \mathrm{~s}$, FVC forced vital capacity Asthma uncontrolled: $\mathrm{ACT}<20$, Asthma partly controlled: $20 \leq \mathrm{ACT} \leq 24$, Asthma controlled: $\mathrm{ACT}=25$

a Adjusted for age, BMI, eosinophil count, IgE, HR, FEV1, FEV1\%pred, FVC, FEV1/FVC, FEV1-post inhaling short-acting bronchodilator, FVC-post inhaling short-acting bronchodilator, FEV1/FVC-post inhaling short-acting bronchodilator

b Adjusted for age, BMI, eosinophil count, IgE, HR, FEF50, FEF50\%pred, FEF75, FEF75\%pred, FEF25-75, FEF25-75\%pred

c Lung function after inhaling short-acting bronchodilator

FEF25-75 after inhaling short-acting bronchodilator were respectively associated with better asthma control. It may contribute to identifying the endotype of asthma by further clarifying the relationship between airway bronchodilator reversibility, obstruction in small airway, Th2-biomarkers and disease control after initial treatment.

In the present study, asthmatic patients with HR were showed a higher level of Th2-biomarkers than LR group. That finding was similar with previous report [4]. Moreover, in comparison with that previous study, we found that not only serum IgE level but also blood eosinophil count of patients with HR was higher than those with LR. That may be mainly due to different characteristics of our subjects from that previous study. In our study, all patients received ICS combined LABA treatment. ICS could affect circulating eosinophil counts and cytokine expression [9]. In addition, Chinese demographics and clinical characteristics of populations in our study may partly contribute to our different findings. In our study, Chinese patients were showed a lower baseline lung function, a higher level of Th2biomarkers than Europeans in previous study [4]. Thus, Th2-biomarkers may be more related with HR endotype than LR in Chinese patients with asthma.

Interestingly, it didn't find an association between Th2 biomarker and asthma control after the first-month initial treatment in our study. Previous study found that asthmatic patients with higher blood eosinophil counts fared poorer asthma control [10]. However, that study followed subjects for a long term, and didn't combine with the phenotype of HR. Thus, our study suggested that for patients with HR, higher Th2-biomarkers may not indicate poorer disease control after a short-term initial treatment. Blood eosinophil counts as a biomarker of asthma control in patients with HR phenotype may be combined with other biomarkers. Future study with larger sample size is needed to confirm our findings.

FEF50, FEF75 and FEF25-75 in baseline of patients with HR were less than those with LR in our study. FEF75 and FEF25-75 could accurately reflect flow at low lung volumes, which is helpful to showing small airway obstruction in early stage of obstructive lung disease $[11,12]$. Particularly, FEF25-75 is a sensitive indicator for obstructive small airway disease [13]. Thus, asthmatic patients with HR may have a higher risk for small airway obstruction than those with LR. Furthermore, we assessed the association between asthma control after initial treatment and FEF75 or FEF25-75 postinhaling bronchodilator. We found that FEF25-75 postinhaling bronchodilator was associated with a decreased risk of poor asthma control, suggesting that high FEF25-75 post-inhaling bronchodilator may indicate better asthma control. Since FEF25-75 is an effective indicator for asthma control [14], FEF25-75 post-inhaling bronchodilator may 
be a desirable indicator for asthma control after short-term initial treatment in the endotype of HR.

Furthermore, the present study showed that HR was associated with a decreased risk of poor asthma control after the first-month initial treatment. In contrast, previous study found that patients with higher airway reversibility were showed worse controll of asthma at 12 month-follow-up [15]. These findings suggested that asthmatic patients with HR may have a better response than those with LR at the beginning of initial treatment with ICS combined with LABA. However, the longterm response to that treatment may be not good in patients with HR as previous reported [15]. The factors are not well clarified. It may be partly related with complex pathogenesis and progress of asthma, variously adjustment in therapeutic strategies during long-term treatment, or patients' incompliance with treatment. Thus, for patients with $\mathrm{HR}$, it may be particularly important to regularly monitor disease control and then adjust therapeutic strategy in a long term.

We acknowledge that our study has limitations. The patients were followed only 1 month after initial treatment. Although we can't explore asthma control of HR group in a long-term, previous study reported different findings on asthma control in patients with HR for a long-term from a short-term [15]. Those indicated that there may be dynamic changes of asthma control during a long period of treatment. Moreover, atopy test was absent in our study. Thus, we couldn't explore the relationship between atopy and HR endotype. Even though, the self-reported history of allergy was not significant different between HR and LR groups when demographic characteristics were well matched.

\section{Conclusions}

In conclusion, HR is a physiologic indicator of lower lung function, particularly small airway obstruction, and is more related with an increased level of Th2-biomarkers than LR. Moreover, HR indicates well asthma control after the first-month initial treatment. Those findings may be help to identify the endotype of asthma.

\section{Abbreviations \\ GINA: Global Initiative for Asthma guidelines; ACT: Asthma Control Test; FEV1: forced expiratory volume in one second; Th2: T-helper 2; COPD: chronic obstructive pulmonary disease; HR: high airway reversibility; LR: low airway reversibility; OR: odds ratios; Cl: confidence intervals; SD: standard deviation; BMI: body-mass index; ICS: inhaled corticosteroid; LABA: long-acting inhaled B2-agonist; FEF: forced expiratory flow.}

\section{Authors' contributions}

JW, BM and SC designed the study. JW, LM, JW, QX, MC, MJ, ML, WJ and WS coordinated the overall undertaking of the study. JW and SC performed statistical analyses. JW and SC wrote the manuscript. All authors contributed to the revision. All authors read and approved the final manuscript.

\begin{abstract}
Author details
${ }^{1}$ Department of Respiratory and Critical Care Medicine, Affiliated Hospital of Guilin Medical University, Guilin 541001, Guangxi, China. ${ }^{2}$ Laboratory of Respiratory Diseases, Affiliated Hospital of Guilin Medical University, Guilin 541001, Guangxi, China.
\end{abstract}

\section{Competing interests}

The authors declare that they have no competing interests.

\section{Availability of data}

The datasets used and/or analyzed during the current study are available from the corresponding author on reasonable request.

\section{Consent for publication}

Not applicable.

\section{Ethics approval and consent to participate}

The study protocol was approved by the Institutional Review Board at the Affiliated Hospital of Guilin Medical University, and conformed to the declaration of Helsinki. Written informed consent was obtained from each subject.

\section{Funding and acknowledgements}

This work was supported by grants from the National Natural Science Foundation of China (Nos. 81460005 and 81760008), the Guangxi Natural Science Foundation (Nos. 2012GXNSFDA053020 and 2015GXNSFAA139107).

\section{Publisher's Note}

Springer Nature remains neutral with regard to jurisdictional claims in published maps and institutional affiliations.

Received: 15 September 2018 Accepted: 20 December 2018

Published online: 27 December 2018

\section{References}

1. Global strategy for asthma management and prevention 2014. Global Initiative for Asthma website. http://www.ginasthma.org/. Accessed 1 Aug 2014.

2. Busse WW, Holgate S, Kerwin E, Chon Y, Feng J, Lin J, et al. Randomized, double-blind, placebo-controlled study of brodalumab, a human anti-IL-17 receptor monoclonal antibody, in moderate to severe asthma. Am J Respir Crit Care Med. 2013;188(11):1294-302.

3. Nadeau M, Boulay MĖ, Milot J, Lepage J, Bilodeau L, Maltais F, et al. Comparative prevalence of co-morbidities in smoking and non-smoking asthma patients with incomplete reversibility of airway obstruction, non-smoking asthma patients with complete reversibility of airway obstruction and COPD patients. Respir Med. 2017;125:82-8.

4. Busse WW, Holgate ST, Wenzel SW, Klekotka P, Chon Y, Feng J, et al. Biomarker profiles in asthma with high vs low airway reversibility and poor disease control. Chest. 2015;148(6):1489-96.

5. Agache IO. From phenotypes to endotypes to asthma treatment. Curr Opin Allergy Clin Immunol. 2013;13(3):249-56.

6. Vega JM, Badia X, Badiola C, López-Viña A, Olaguíbel JM, Picado C, et al. Validation of the Spanish version of the Asthma Control Test (ACT). J Asthma. 2007;44(10):867-72.

7. Jia CE, Zhang HP, LV Y, Liang R, Jiang YQ, Powell H, et al. The Asthma Control Test and Asthma Control Questionnaire for assessing asthma control: systematic review and meta-analysis. J Allergy Clin Immunol. 2013;131(3):695-703.

8. Diagnosis of diseases of chronic airflow limitation: asthma, COPD and asthma COPD overlap syndrome. Global initiative for chronic obstructive lung disease website. http://www.goldcopd.org/uploads/users/fles/ AsthmaCOPDOverlap.pdf. Accessed 25 Aug 2014.

9. Anderson WJ, Short PM, Jabbal S, Lipworth BJ. Inhaled corticosteroid dose response in asthma: should we measure inflammation? Ann Allergy Asthma Immunol. 2017;118(2):179-85

10. Price DB, Rigazio A, Campbell JD, Bleecker ER, Corrigan CJ, Thomas M, et al. Blood eosinophil count and prospective annual asthma disease burden: a UK cohort study. Lancet Respir Med. 2015;3(11):849-58. 
11. Pereira CA, Barreto SP, Simões JG, Pereira FW, Gerstler JG, Nakatani J. Valores de referência para espirometria em uma amostra da população brasileira adulta. J Pneumol. 1992;18(1):10-22.

12. Rodrigues MT, Fiterman-Molinari D, Barreto SS, Fiterman J. The role of the FEF50\%/0.5FVC ratio in the diagnosis of obstructive lung diseases. J Bras Pneumol. 2010;36(1):44-50.

13. Simon MR, Chinchilli VM, Phillips BR, Sorkness CA, Lemanske RF Jr, Szefler SJ, et al. Forced expiratory flow between 25 and $75 \%$ of vital capacity and FEV1/forced vital capacity ratio in relation to clinical and physiological parameters in asthmatic children with normal FEV1 values. J Allergy Clin Immunol. 2010;126(3):527-34.e1-8.
14. Lutfi MF Patterns of changes and diagnostic values of FEF $50 \%$, FEF25\% $75 \%$ and FEF50\%/FEF25\%-75\% ratio in patients with varying control of bronchial asthma. Int J Health Sci (Qassim). 2016;10(1):3-11.

15. Khusial RJ, Sont JK, Loijmans RJB, Snoeck-Stroband JB, Assendelft PJJ, Schermer TRJ, et al. Longitudinal outcomes of different asthma phenotypes in primary care, an observational study. NPJ Prim Care Respir Med. 2017;27(1):55
Ready to submit your research? Choose BMC and benefit from:

- fast, convenient online submission

- thorough peer review by experienced researchers in your field

- rapid publication on acceptance

- support for research data, including large and complex data types

- gold Open Access which fosters wider collaboration and increased citations

- maximum visibility for your research: over $100 \mathrm{M}$ website views per year

At BMC, research is always in progress.

Learn more biomedcentral.com/submissions 